\title{
Carga viral en pacientes pediátricos VIH positivos con terapia antirretroviral
}

\author{
Leticia Porto-Espinoza ${ }^{1 a}$, Reyna Moronta ${ }^{1,2 a}$, César \\ Cuadra-Sánchez ${ }^{12}$, Diana Callejas-Valero ${ }^{36}$, Luciana \\ Costa-León $^{3 c}$, Francisca Monsalve-Castillo ${ }^{3 d}$, Cecilia \\ Bernardoni $^{4}$, Jesús Estévez ${ }^{5}$.

\section{Viral loads in pediatric HIV patients with antirretroviral treatment}

Background: Viral load in pediatric patients with HIV infections can help to make therapeutic decisions to modify the evolution of the disease. Aim: To evaluate viral load in positive HIV children with antiretroviral treatment. Material and methods: Viral load was measured every six months during three years in fifty pediatric patients chosen randomly in aged 1 to 12 years, using the Test Monitor HIV-1 AMPLICOR, version 1.5. Results: During the three years follow up, there was an increase in CD4 and CD8 lymphocyte count and decrease in the viral load. However, there was no significant relationship between lymphocyte subpopulation counts and viral loads. Conclusions: Viral load demonstrated to be an appropriate method to quantify plasma HIV-RNA. This tool can help to define the condition of a particular patient to predict clinical course of the disease and to assess the response to the treatment (Rev Méd Chile 2008; 136: 1021-6).

(Key w ords: Antiretroviral therapy, highly active; HIV-1; Viral load)

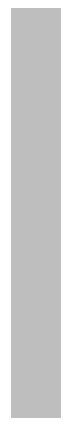

\footnotetext{
Recibido el 23 de mayo, 2007. Aceptado el 20 de marzo, 2008.

${ }^{1}$ Laboratorio Regional de Referencia Virológica, Instituto de Investigaciones Clínicas, Facultad de Medicina, Universidad del Zulia, Maracaibo-Venezuela. ${ }^{2}$ Cátedra de Biología Celular y Genética, Departamento de Biología, Facultad de Humanidades y Educación, Universidad del Zulia. Maracaibo, Venezuela. ${ }^{3}$ Cátedra de Virología, Escuela de Bioanálisis, Facultad de Medicina, Universidad del Zulia, Maracaibo-Venezuela. ${ }^{4}$ Fundación Innocens, Hospital Universitario de Maracaibo, Zulia-Venezuela. ${ }^{5}$ Instituto de Investigaciones Clínicas, Facultad de Medicina, Universidad del Zulia, Maracaibo-Venezuela. aLicenciado en Biología, M.Sc. Microbiología

bLicenciada en Biología, M.Sc. Inmunología

'Licenciada en Biología, M.Sc. Ciencias Ambientales

dLicenciada en Bioanálisis, M.Sc. Inmunología
}

Correspondencia a: Leticia Porto-Espinoza. Telefax: 0582617597273-31, Apartado postal 23, Código Postal 4001A.

E mail: letiporto@yahoo.com 
$\mathrm{E}^{1}$ virus de inmunodeficiencia humana (VIH), causante del síndrome de inmunodeficiencia adquirida (SIDA), se ha difundido a nivel mundial, siendo una enfermedad compleja, tanto en el ámbito biológico como en su repercusión social $^{1,2}$. La infección por este virus en la edad pediátrica es un cuadro grave y sintomático, cuya evolución natural determina que una cuarta parte de los pacientes cumplan criterios de SIDA antes del año y no sobrevivan más de 3 años, lo que requiere una intervención terapéutica precoz y un control estricto de la efectividad de la terapia ${ }^{3-5}$.

Es un gran reto determinar el momento apropiado para iniciar, o interrumpir el tratamiento, y así lograr un pronóstico benéfico a largo plazo para los niños. La evidencia demuestra que empezar la terapia antirretroviral temprano durante la infección aguda es beneficioso a largo plazo ${ }^{6,7}$. Sin embargo, la larga duración del tratamiento aumenta la probabilidad de desarrollar un virus resistente al medicamento y la terapia continuada que empieza a temprana edad conduce a complicaciones a largo plazo en los niños ${ }^{4}$.

El nivel de virus en la sangre (carga viral) es un factor predictivo del avance de la enfermedad por el VIH; las personas con altos niveles de ARN viral tienen mayor probabilidad de presentar rápido desarrollo de esta patología que las personas con bajos niveles ${ }^{1,8}$. La carga viral es un marcador de la actividad del VIH-1, determina la etapa de la infección en la que se encuentra el paciente, además, se considera uno de los indicadores del estado del sistema inmunológico y de la progresión de la enfermedad, solo o en conjunción con el conteo de células CD49,10.

Existen pocas investigaciones que muestren el estado inmune de los niños con VIH, siendo la carga viral útil para determinar este estado $\mathrm{y}$ orientar al médico en la toma de decisiones en cuanto a la elección y cambios terapéuticos necesarios para modular el curso de la infección, mejorando la calidad de vida y tiempo de supervivencia de los pacientes pediátricos con VIH. El objetivo de este estudio es evaluar la carga viral como parámetro de evolución y eficacia de diferentes estrategias antirretrovirales en niños VIH positivos.

\section{Pacientes y MÉTOdos}

Población de estudio y criterios de selección: Se estudió la población total de pacientes pediátricos de la Fundación Innocens, la cual fue de 50 niños en edades de 1 a 12 años, sin distinción de sexo y diversa condición social, con infección de VIH por transmisión vertical y con tratamiento antirretroviral. Estos pacientes fueron evaluados en un período comprendido de 3 años.

A cada paciente se le realizó una historia clínica, cuyos datos fueron aportados por los representantes legales, quienes dieron su consentimiento informado por escrito, bajo las normas del código de Bioética y Bioseguridad del FONA$\mathrm{CIT}^{11}$. A los niños se les realizó un estudio clínico y de laboratorio, donde se determinó que todos se encontraban en buenas condiciones clínicas y asintomáticos, correspondiente a la categoría A1 del esquema de clasificación del $\mathrm{CDC}^{12}$.

Toma de muestra y determinación de la carga viral: A cada paciente se le tomó 10 cc de sangre venosa en tubos Vacutainer con EDTA. Esta muestra fue dividida en dos alícuotas: 5cc fueron centrifugados para obtener el plasma, el cual se almacenó a $-20^{\circ} \mathrm{C}$ para la cuantificación de carga viral del VIH mediante la técnica de AMPLICOR HIV-1 Monitor Test, versión 1.5 y el resto de la muestra se utilizó para el recuento de linfocitos CD4 y CD8 mediante citometría de flujo, según la técnica descrita por Moronta y $\mathrm{col}^{13}$. Estas determinaciones fueron realizadas 2 veces por año y se tomaron en cuenta como parámetros de eficacia de los tratamientos antirretrovirales.

Tratamientos suministrados: Los tratamientos antirretrovirales suministrados a los 50 pacientes pediátricos fueron indicados por médicos pediatras especialistas en el área. Esta terapia consistió de tres tipos de medicamentos simultáneos que incluyeron inhibidores de transcriptasa inversa: zidovudina (AZT), stavudina (dT4), lamivudina (3TC), abacavir (Ziagen ${ }^{\circledR}$ ), neviparina y dos inhibidores de proteasa: nelfinavir, lopinavir/ritonavir $\left(\right.$ Kaletra $\left.{ }^{\circledR}\right)$. El número de pacientes a los cuales se les indicó la terapia antirretroviral se muestra en la Tabla 1. 
Tabla 1. Pacientes que recibieron tratamiento antirretroviral

\begin{tabular}{|cl|}
\hline Número de pacientes & Tratamiento antirretroviral \\
\hline 9 & AZT+3TC+nelfinavir \\
8 & AZT+neviparina+nelfinavir \\
8 & 3TC+abacavir+nelfinavir \\
8 & 3TC+neviparina+lopinavir/ritonavir \\
9 & dT4+neviparina+lopinavir/ ritonavir \\
8 & dT4+abacavir+lopinavir/ ritonavir \\
\hline
\end{tabular}

Estadística. Los resultados se analizaron a través del programa SPSS para Windows, versión 11, 2.001, y se presentaron en forma de tabla de distribución de frecuencia. Las variables se estudiaron por análisis de varianza (ANOVA), el análisis de Kruskal-Wallis según correspondiera, y el post-análisis de Tukey. La relación de las variables obtenidas en las determinaciones de cada población, se analizaron empleando el test de correlación de Pearson. Se tomó como índice de confianza el $95 \%$, considerándose como significativo todo valor de probabilidad menor a 0,05 $(\mathrm{p}<0,05)$.

\section{RESULTADOs}

En la Tabla 2 se muestran los promedios de los valores de CD4, CD8 y carga viral en los tres años de estudio con respecto a la edad de los niños, no encontrándose diferencias significativas $(p>0,05)$; sin embargo, se observa una elevación de los niveles de CD4 y CD8 y una disminución de la carga viral.

La Tabla 3 muestra los valores logarítmicos de las concentraciones de CD4, CD8 y carga viral, donde no se obtuvo ninguna diferencia significativa, ya que las probabilidades fueron mayores a $0,05(\mathrm{p}>0,05)$. Esta transformación loganítmica se realizó, por trabajar con altos valores de desviación estándar tanto para los CD4 y CD8, como para la carga viral, al fin de disminuir el impacto de esta desviación, y aún así no se encontró diferencias significativas en ninguno de los tres años de investigación.

En la Figura 1 se observa la carga viral en relación con los tratamientos antirretrovirales y se evidencia que el percentil 25 es mayor que el percentil 50 en la mayoría de los tratamientos $\left(\mathrm{P}_{25}>\right.$ $\mathrm{P}_{50}$ ), indicando una diferencia significativa entre los tratamientos. De los tratamientos suministrados, los antimetrovirales AZT+3TC+Nelfinavir y dT4+neviparina+lopinavir/ ritonavir mantienen la carga viral baja y 3TC+abacavir+nelfinavir y dT4+abacavir+lopinavir/ritonavir carga viral alta.

Tabla 2. Niveles de CD 4, C D 8 y carga viral en los tres años de estudio con respecto a la edad de los niños

\begin{tabular}{|llllll|}
\hline Año & $\begin{array}{l}\text { Edad } \\
\text { (Años) }\end{array}$ & $\begin{array}{l}\text { CD4 (cel/ml) } \\
\text { Promedio } \pm D S\end{array}$ & $\begin{array}{l}\text { CD8 (cel/ml) } \\
\text { Promedio } \pm D S\end{array}$ & $\begin{array}{l}\text { CD4/CD8 } \\
\text { Promedio } \pm D S\end{array}$ & $\begin{array}{l}\text { Carga viral (Copias } \\
\text { ARN/ml) Promedio } \pm D S\end{array}$ \\
\hline 1 & $1-6$ & $936 \pm 662$ & $1216 \pm 918$ & $0,86 \pm 0,4$ & $94200 \pm 91663$ \\
& $7-12$ & $560 \pm 397$ & $976 \pm 641$ & $0,62 \pm 0,3$ & $66122 \pm 102249$ \\
2 & $1-6$ & $1244 \pm 1320$ & $1723 \pm 1608$ & $1,01 \pm 1,4$ & $42466 \pm 41244$ \\
& $7-12$ & $852 \pm 751$ & $1183 \pm 779$ & $0,76 \pm 0,4$ & $35575 \pm 27461$ \\
3 & $1-6$ & $1301 \pm 1231$ & $1571 \pm 1381$ & $0,85 \pm 0,33$ & $23050 \pm 12789$ \\
& $7-12$ & $874 \pm 501$ & $1183 \pm 401$ & $0,69 \pm 0,34$ & $4617 \pm 9741$ \\
\hline
\end{tabular}

(cel/ml): células/mililitros; DS: Desviación Estándar. 
Tabla 3. Correlación de los valores logarítmicos de C D 4 y C D 8 y la carga viral

\begin{tabular}{|ccccc|}
\hline & Año 1 & Año 2 & Año 3 \\
\hline & & Log 10 Carga viral & Log 10 Carga viral & Log 10 Carga viral \\
Log 10 CD4 & $\mathrm{r}$ & 0,055 & $-0,208$ & 0,055 \\
& $\mathrm{p}$ & 0,865 & 0,230 & 0,707 \\
Log 10 CD8 & $\mathrm{r}$ & 0,102 & $-0,174$ & $-0,326$ \\
& $\mathrm{p}$ & 0,484 & 0,318 & 0,056 \\
\hline
\end{tabular}

r: Coeficiente; p: Probabilidad

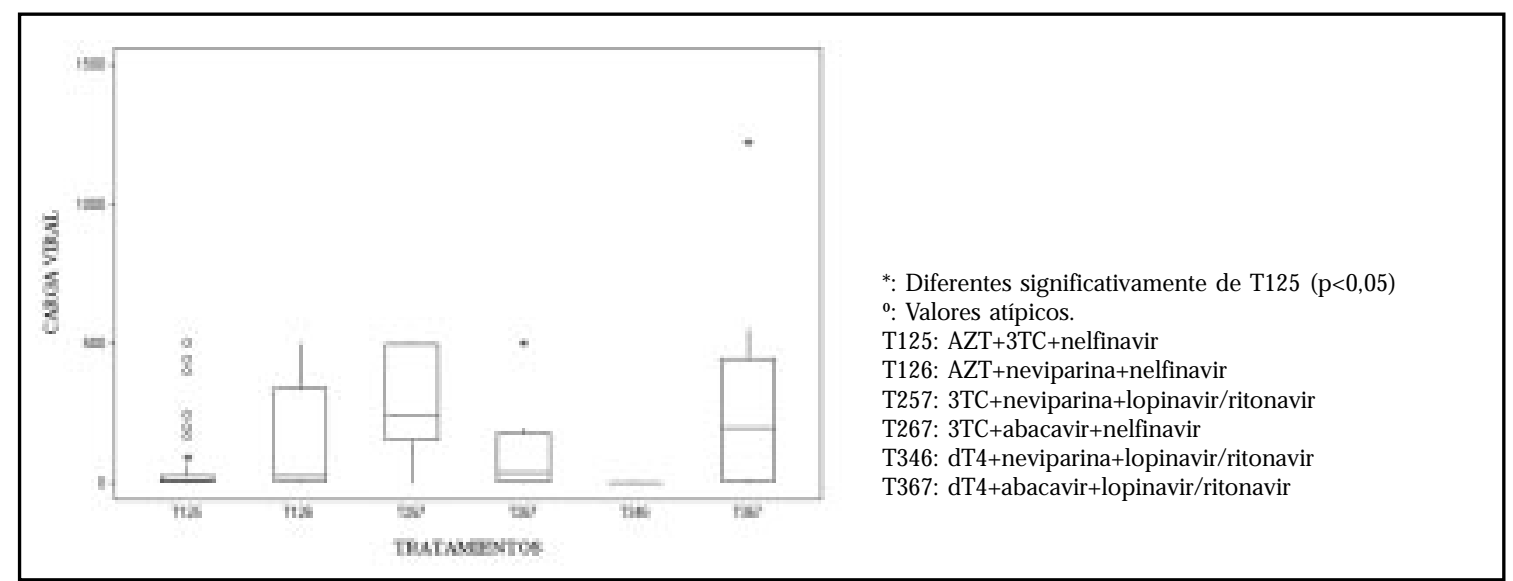

Figura 1. Carga viral en relación a los tratamientos

El análisis de Kruskal-Wallis para evaluar el efecto del tratamiento sobre la carga viral reveló una diferencia significativa $(p<0,05)$, mostrando que los tratamientos difieren. Seguidamente, se aplicó la prueba de Tukey para verificar cuál o cuáles tratamientos son los responsables de las diferencias significativas anunciadas por la prueba $F$ de Fisher-Snedecor.

La prueba de Tukey confirmó los resultados obtenidos en la Figura 1, donde los tratamientos que tienen diferencias significativas $(p<0,05)$ son: AZT+3TC+nelfinavir con el 3TC+abacavir+nelfinavir y con el dT4+abacavir+lopinavir/ ritonavir. Los tratamientos restantes no mostraron diferencias significativas $(\mathrm{p}>0,05)$.

\section{DISCUSIÓN}

La presente investigación mostró que los niveles de CD4 y CD8 se elevan y la carga viral disminuye. Sin embargo, el análisis de la relación de la carga viral con los niveles de CD4, CD8, CD4/CD8 no mostraron diferencias significativas $(p>0,05)$, lo cual puede deberse a un estado inmunitario inmaduro 0 a la gran heterogeneidad de los valores de CD4 y de la carga viral en los rangos de edad de los pacientes estudiados. La tendencia observada, aunque no significativa, podría indicar una posible relación inversa entre los niveles de inmunidad celular y la concentración viral presente. Estos resultados coinciden con los reportados en otros estudios ${ }^{9,10,14}$. 
Los niveles de CD4 de los niños con VIH para que sean inmunocompetentes deben estar dentro de los siguientes rangos: $>1.000-1.499$ para el grupo etario de 1-6 años y >500-999 para el de 712 años $^{15}$. Durante este estudio se observaron niveles de CD4 elevados en todos los pacientes (Tabla 2), considerándose los mismos inmunocompetentes y demostrando con ello que estaban respondiendo a los tratamientos antirretrovirales.

También se mantuvieron altos los niveles de CD8 y la relación CD4/CD8 tanto en niños de 1 a 6 años como de 7-12 años. Se detectó que en los niños de menor edad la carga viral fue elevada e iba disminuyendo a medida que se incrementaba la edad (Tabla 2). Esto es semejante a lo reportado en otro estudio ${ }^{16}$, donde se indica que los niños son particularmente susceptibles a los efectos del virus, ya que su sistema inmunitario no se ha desarrollado completamente en el momento de la infección primaria, mostrando así un índice elevado de carga viral y de rápido progreso de la enfermedad en los primeros años de vida.

La carga viral de los niños infectados por VIH es proporcionalmente más elevada que en adultos. Tal como se ha observado en este estudio, los niños infectados verticalmente presentan un descenso gradual de la carga viral a medida que aumenta la edad, por lo que es importante realizar al menos dos determinaciones de carga viral antes de tomar cualquier decisión sobre el tratamiento a utilizar, ${ }^{7,17}$.

Otro parámetro que va a predecir la evolución del niño es el recuento de CD4, que conjuntamente con la carga viral y la condición clínica, orientan la terapia antirretroviral a aplicar. La valoración de la respuesta al tratamiento, se debe hacer estimando carga viral y CD4, ya que sus variaciones o alteraciones son más visibles que cualquier situación clínica. El control de los parámetros de carga viral y CD4 realizados en este estudio permitió modificar el tratamiento antirretroviral.

No se encontró relación entre la edad de los pacientes y la carga viral en los tres años de estudio.

El porcentaje de niños con carga viral indetectable fue $19 \%, 52 \%$ y $48 \%$ para cada uno de los 3 años de estudio. Esto es un resultado interesante, que coincide con el inicio de la evaluación de la carga viral, lo cual permitió realizar el monitoreo y tomar decisiones en el cambio de la terapia, ayudando así a elegir el tratamiento más eficaz; que logró mantener una carga viral indetectable en la mayoría de los niños. Estos valores coinciden con los obtenidos por otros investigadores ${ }^{18}$ quienes demostraron carga viral indetectable en $19,2 \%$ de niños con tratamiento antirretroviral; con el tiempo, a medida que se seguía evaluando la carga viral en dichos niños, aumentaba el porcentaje $(57,2 \%)$ de niños con carga viral baja o indetectable.

Con respecto a la eficiencia de la terapia antirretroviral en niños VIH positivos, se obtuvo que existen diferencias significativas entre los tratamientos, debido a que el percentil 25 es mayor que el percentil $50\left(\mathrm{P}_{25}>\mathrm{P}_{50}\right)$ en la mayonáa de los tratamientos (Figura 1). De las terapias triasociadas de antirretrovirales medicados el AZT+3TC+nelfinavir y el dT4+neviparina+lopinavir/ritonavir, fueron los tratamientos que disminuyeron en mayor proporción los niveles de ARN del VIH, mientras que el 3TC+abacavir+nelfinavir y el dT4+abacavir+lopinavir/ nitonavir, se asociaron a cargas virales más altas. En tal sentido, es relevante enfatizar que a estos últimos tratamientos, sólo se les cambió un análogo de nucleósido inhibidor de transcriptasa inversa (TI) por otro como el abacavir.

Los resultados obtenidos en esta investigación son similares a los encontrados por otros autores $^{4,16}$ con respecto a los dos tratamientos empleados que incluían el abacavir, donde la carga viral se mantenía elevada. Ellos observaron que el abacavir+3TC+AZT fue capaz de reducir la carga viral, teniendo $75 \%$ de 87 pacientes menos de 400 copias/ml comparado con $35 \%$ de 86 pacientes de la terapia dual y los cambios de CD4 no mostraron diferencias significativas entre los dos grupos.

Para probar la interacción entre la terapia triasociada, el tiempo del estudio (años) sobre la carga viral, se realizó un análisis de varianza para mediciones repetidas, lo cual evidenció que no existe efecto de interacción entre estas variables, puesto que no se determinó ninguna diferencia significativa entre las mismas.

Basado en estos resultados, y los obtenidos en otros estudios ya discutidos anteriormente, podemos señalar que la carga viral es un índice confiable de la evolución de la enfermedad; sin embargo, al tratarse de niños debemos ser meticulosos para guiar las decisiones sobre el tratamiento individual y para evaluar si los fármacos anti VIH están siendo efectivos o no, durante los ensayos clínicos, por lo que conviene determinar 
la carga viral junto con el recuento de CD4, la edad y el estado clínico del paciente.

El control regular de la carga viral permite a los médicos tomar decisiones más tempranas sobre el tratamiento, antes de presentar una disminución significativa de los linfocitos CD4 y mucho antes de experimentar el deterioro clínico. Se cree que la disminución de la cantidad de CD4 ocurre relativamente tarde en el proceso de la enfermedad, resultante de incrementos en la replicación del $\mathrm{VIH}^{17-19}$. Por esta razón, parece ser más beneficioso hacer decisiones sobre el tratamiento anti VIH basado en la carga viral en vez de sólo en el número CD4, particularmente cuando el número $\mathrm{CD} 4$ es mayor de 500 linfocitos por $\mathrm{mm}^{3}$.

En función que la recolección de los datos de niños VIH positivos es muy limitada, se considera

\section{REFERENCIAS}

1. Cavazza M, Correnti M. Determinación de la carga viral de VIH y su importancia clínica. Rev Fac Med (MSAS-UCV) 1999; 22: 11-5.

2. Slafsman J, Goodenow M. Immunologic Disorders. HIV1 infection. J Allergy Clin Inmunol 2003; 111: 1-22.

3. CEvihp FC. Manual Práctico de la Infección VIH pediátrica. 2 ${ }^{\mathrm{a}}$ Edición. De Prous. Barcelona 2000.

4. Van Rossum A, Fraij P, Groot R. Efficacy of highly active antiretroviral therapy in HIV-1 infected children. Lancet Infect Dis 2002; 2: 1-21.

5. Horwood C, Liebeschuetz S, BlaAuw D, Cassol S, Qazi S. Diagnosis of pediatric HIV infection in a primary health care setting with a clinical algorithm. Bull World Health Organ 2003; 81: 858-66.

6. KiLBY J, ERON J. Novel Therapies Based on Mechanisms of HIV-1 Cell Entry. New England J Med 2003; 348: 2228-38.

7. González M, Ramos J, Sánchez J, Guilén S, Rojo P, RuIs J. Efectividad de la terapia antirretroviral en niños con infección por VIH-1. Corte transversal. Ann Pediatric 2005; 62: 32-7.

8. SaAg Ms, Holodniy M, Kuritzkes D, O’Brien W, COOMBS, JACOBSEN D ET AL. HIV viral load markers in clinical practice. Nat Med 1996; 2: 625-9.

9. Paul M, Shearer W, Koninetz C, Lewis D. Basic and Clinical Immunology. Comparison of CD8+ T-cell subsets in HIV-infected rapid progressor children versus non-rapid progressor children. J Allergy Clin Inmunol 2001; 108: 1-14.

10. Chinen J, Shearer W. Molecular virology and immunology of HIV infection. J Allergy Clin Inmunol 2002; 110: 1166-86. que se hace necesaria posteriores estudios con poblaciones mayores que permitan describir de forma más amplia las variaciones de los parámetros analizados en esta investigación.

Hasta la fecha son escasos los trabajos realizados sobre carga viral en niños VIH positivos a nivel mundial y sobre todo en Venezuela, siendo este estudio uno de los pioneros en nuestra región y como tal, se espera que sirva como base para estudios posteriores destinados a conocer la utilidad de la carga viral como herramienta para definir el estado del paciente y predecir el curso clínico de la enfermedad.

Agradecimientos

Los autores agradecen a los niños y a sus representantes, así como al personal de la Fundación Innocens por su valiosa colaboración y aporte a esta investigación.

11. Briceño E, Suárez E, Michelangi C, Feluciangeli D, Otaiza E, Mendible J et AL. Código de Bioética y Bioseguridad, Capítulos 2 y 3. 2aㅡ ed.; Ministerio de Ciencia y Tecnología (FONACIT) Caracas 2002.

12. Centers for Disease Control. 1993 Revised classification system for VIH infection and expaned surveillance case definition for AIDS among adoledcents and adults. MMWR 41 (No. RR-17) 1992.

13. Moronta R, Porto L, Cuadra C, Lueras A, Vilualobos H, ARaujo M ET AL. Determinación de linfocitos T CD4 y CD8 en niños VIH positivos con terapia. Vitae 2006; 26: 1-7.

14. Vigan A, Pinti M, Nasi M, Moretti L, BaLi F, Mussini C ET AL. Markers of cell death-activation in lymphocytes of vertically children naive to highly active antirretroviral therapy: The role of age. Basic Clin Inmunol 2001; 108: 1-13.

15. McKenzie S. Hematología Clínica. 2a Edición. Editorial Manual Moderno 2000.

16. Chiappini E, Gaui L, Azzari C, De Martino M. Nitric oxide in HIV-1 perinatally infected children treated with highly active antiretroviral therapy. Lancet Infect Dis 2003; 3: 341-6.

17. Reuben J, Lee B, Paul M, Kune M, Cron S, Abramson S ET AL. Magnitude of IFN-g production in HIV-1infected children is associated with virus suppression. J Allergy Clin Immunol 2002; 110: 1-13.

18. Mesino S, BeLón J, León J, Mesino R, Muñoz M. Carga viral plasmática en niños infectados por el virus de la inmunodeficiencia humana que reciben tratamiento antirretroviral de gran actividad. Medicina Clínica 2007; 128: 49-51.

19. Kotler D. Human immunodeficiency virus and pregnancy. Gastroenterol Clin 2003; 32: 1-11. 